\title{
Embedded System and Robotic Education in a Blended Learning Environment Utilizing Remote and Virtual Labs in the Cloud, Accompanied by 'Robotic HomeLab Kit'
}

\author{
http://dx.doi.org/10.3991/ijet.v7i4.2245 \\ R. Sell ${ }^{1}$, S. Seiler ${ }^{2}$ and D. Ptasik ${ }^{2}$ \\ 1 Tallinn University of Technology, Tallinn, Estonia \\ 2 Bochum University of Applied Sciences, Bochum, Germany
}

\begin{abstract}
It is impossible to imagine everyday life without embedded devices and robotic applications, as they are utilized in almost every nowadays technical product. And there is a frantic need of well-educated developers, designers and programmers to handle and further evolve this existing technology. The domain itself is in a big change because the borders of pure ICT and embedded system are fusing and according to this process new methods for teaching these disciplines are necessary. It is important that ICT education will become more and more to real systems education, instead of just computer software programming, but in most curricula these two domains are still separated. The paper addresses a novel and implemented solution for teaching and learning of Robotics and embedded systems, while setting in remote labs and modern Internet technology into overall learning process. The proposed concept builds the bridge for a simple and logical study process by utilizing ICT for controlling and understanding real word processes and situations. The introduced blended learning concept covers several educational levels, starting from first and second level education up to university education and lifelong learning. The solution is covered with hands-on mobile hardware kits, collaborative e-tools and remote labs. The focus in this paper is on the integration of the overall concept and an evaluation of the given courses.
\end{abstract}

Index Terms-Telerobotics, Educational products, Educational robots, International collaboration, Internet assisted laboratories

\section{INTRODUCTION}

Interest in the Robotics field has increased a lot in the last years. Robotics is offering new benefits for teaching in multidisciplinary disciplines like Mechatronics at all educational levels. It offers an "efficient" way for teaching Electronics, Computer Science as well as Mechanical Engineering within one research objective. Nowadays it is important to attract learners with state-of-the-art equipment and technology to keep them trying to evolve their technical skills and extend their overall knowledge. Modern Internet technology determines the daily routine of youngsters quite a lot. Web 2.0 multimedia web pages (for instance YouTube), socializing platforms (for instance Facebook) and online games are the most used websites on the net for youngsters [1]. For instance, an average youngster in Germany at the age of 14-29 spends 168 minutes a day using the computer for accessing the Internet [2]. Therefore a combination of modern Internet Technology and the Robotic education, to exploit this constantly rising development for educational purposes, seems to be a logical process.

In the last years there have been several attempts to enhance the engineering education, especially the robotic one, through technology-enhanced learning, where approaches are focusing on different aspects. Authors in [3] are using virtual reality in engineering education at the University of Warwick, to plan and simulate system behaviour. Ivanović et al [4] come to the conclusion, that by using a LMS, the "assignment and submission of projects is simplified". According to González et al., the "[...] virtual lab model is a more sustainable and scalable alternative than the traditional academic computing lab, as it provides the computing resources required by the learning activities of the students with lower installation and operation costs"[5]. Qidwai in [6] draws the idea that "the use of project-based learning methodology has shown a great increase in motivation and focus on the subject in the students [...]." in the frame of robotics education. The approach presented in this paper enhances Robotic education by Internet assisted parts, to form a blended learning concept, where students are attending ordinary classes in university and continue working with the material at home. This is realized by the utilization of innovative products, like the so named HomeLab kit [7], DistanceLab [8] and the VirtualLab - Virtual Micro Controller Unit (VMCU) [9]. These technical utilities are shortly presented in the next section.

The course and curriculum concepts where this paper focuses on will follow innovative approaches already integrated in the Estonian and German educational system. On-going projects are transferring the presented methods and tools into Finish, British and Lithuanian universities and vocational schools.

Before introducing the novel and comprehensive approach the utilized tools and methods are presented shortly the next section.

\section{EQUIPMENT INVOLVED}

The course equipment is based on hardware systems developed in the frame of several international research projects. It involves most of the aspects and resources the 

ACCOMPANIED BY 'ROBOTIC HOMELAB KIT'

concept offers. First of all, it uses the Robotic HomeLab kits as a lab platform, where students can perform exercises, experiments and development either in classroom or at home. The same kit is used as main controller and base platform for peripheral modules within the later system development. Some extra components are usually needed which are depending from the groups design decisions and current university resources. Additional components can be pre-made Robotic platforms as well as application specific sensors or motors if required. However, by using the same kits, already used in labs, it is possible to build the robots with very low additional costs. The main components involved will be presented in the following subsections. A more detailed technical description of the components can be found in [10-16].

\section{A. Robotic HomeLab kit hardware}

The Robotic HomeLab kit (shown in the hardware cases in Fig. 1 and in the upper centre in Fig. 3) is developed with the participation of the authors. It is a micro controller based, portable lab environment. It can be connected to a PC and operated in computer class, at home or in the workplace. The purpose of the kit is to provide practical and effective hands-on training. The main feature of the Robotic HomeLab kit is its mobility - the case is a small and compact box containing all modules and necessary tools. Taking the current development status into account, the Robotic HomeLab kit offers, for example, hardware and exercises for 7-segment LED display, LCD (alphanumeric as well as a graphical one), sensors (potentiometer, infrared distance measure, ultrasonic distance measure, etc.), different motors (DC, servo, stepper), as well as a networking module (for Bluetooth, Ethernet and ZigBee), a CAN module and USB for direct connection to a PC (for example a student home computer

The Robotic HomeLab kit is supplemented by a specific software library, enabling easy access to the modules and their functionality which is available as open source for all users.

\section{B. Virtual Micro Controller Unit (VMCU)}

The VirtualLab - Virtual Micro Controller Unit (VMCU) [11] is based upon the Robotic HomeLab kit hardware. It is a fully featured, but simulated web environment behaving like real hardware. The VMCU is based on Avrora framework [17] and the Java programming language. It can be used for educational purposes as well as for prototyping and research experiments. The VMCU environment is also accessible through the DistanceLab web system. The current development status involves a virtual User Interface module (the same, but simulated one that belongs to the Robotic HomeLab kit) with 7-segment display, three buttons and three LEDs, graphical LCD and a "virtual robot arm" module that is simulating the Arexx Robot Arm RA1-Pro. The VMCU is a typically cloud application, allowing multiple instances running in parallel, so there is now doubt about limited hardware in class.

\section{Distance Lab}

The developed DistanceLab is composed as a rich Internet platform, where different remote and virtual labs are integrated. At first stage, the DistanceLab provides remote access to microcontroller based embedded systems, which can, but must not base on the Robotic HomeLab kit. In the current development stage external labs can also be integrated, so far as they can be interfaced using the internal defined standards (Lab Description Language). The DistanceLab is designed to facilitate direct programming as well as controlling the connected devices. In case of programmable devices, this is realised using a web bases programming environment and an automatically invoked compiling process. This enables flashing programs directly to the connected devices over the Internet. Some examples for interfaced labs are mobile robots, specific versions of Robotic HomeLab kits with add-on modules for a specific purpose (e.g. automotive study CAN-Module, LCD Display or a motor board) or the Virtual Micro Controller Unit with its various modules.

\section{Learning material}

The hardware and software tools presented are accompanied by various types of learning material, where most are available for free access to everyone. This learning material consists of:

- Network of Excellence (NoE) [18] - The base platform for the self-education with bearing material for learning embedded system programming with the Robotic HomeLab kit as well as with the VMCU. NoE is available in several European languages.

- Textbook "Microcontrollers \& Practical Robotics" [19] - This textbook is available in Estonian and English and currently translated to German. It holds most important information for working with embedded devices and robotic applications that are based on the Robotic HomeLab kit.

- Learning situations for vocational education $[20,21]$ - Ready to implement courses in embedded system programming that can be applied in the daily education. These courses build upon the content of NoE

- Hands-on-lab exercise book [22] - A booklet including exercises and exercise solutions from the NoE in printed form.

This learning material is covered more detailed in the papers [10] and [13]

\section{EMBEDDED SYSTEM AND ROBOTIC SPANNING EDUCATIONAL PATH INTRODUCTION}

The virtual and real hardware components presented in the previous section perform as the technological base for a continuous education approach. Main idea is the integration of the same technology into the regular teaching processes on primary-, secondary- and university level. Figure 1 explains how the presented learning tools function among the addressed levels of education. There are different challenges, exercises and experiments for each level. To show an example on how this concept can be integrated in a concrete educational system, authors will give a short introduction on the current development and integration of this continuous approach in Estonia.

In secondary school level a new state curriculum has been applied officially in Estonia in 2011. One of the major changes is a facultative branch. According to the new rules, every school has to offer at least three options to their students. One of the branches is focused on natural sciences where Robotics is one of the offered courses. Several schools already started Robotic courses 2-3 years ago and now have good experience to include the course into their general curriculum. The main technical aspect of 
teaching Robotics in Estonian general educational institutions is the use of micro controller based Robotic learning kits

\section{A. Primary school level}

The first start with Robotics is usually performed in primary school, where Lego Mindstorm NXT kits are used as hardware platform, as presented in Fig. 1. This approach ensures a rapid start, producing fast results, which is very important to keep the motivation up for the Robotic studies. Within the courses several Lego based Robotic solutions are built and programmed. The best pupils of this field have the possibility to participate in national competitions. .

\section{B. Secondary level}

In high school level the next step is offered and the Robotic platform is changed to the Robotic HomeLab kit. This is a logical step where the playground is moved from toys to more (close to) real systems. Graphical programming is replaced with $\mathrm{C} / \mathrm{C}++$ programming. That way, pupils learn that system behaviour can be independent from the addressed physical system. However the main concept of Robotics: sensor-control-actuator is already familiar and therefore easy to migrate to a new platform. The content of practical projects is also integrated into real life systems (e.g. intelligent control of the smart house). This two-step approach enables to start fast, without losing motivation and reach a high knowledge at the end of high school studies in a quite low course workload.

\section{Vocational education}

The case study in vocational school includes around ten different institutions where the Robotics is a course of the Mechatronics, Computer Science or Electrical Engineering curriculum. The main difference in comparison to the high school approach is that the content can be related to other parallel courses like electronics, logics, programming, etc. There is no need to start with Lego any more as the vocational students are already familiar with the field. However the lack of robotic knowledge is still an issue even among vocational school students but may vary between different schools and their speciality. Another main difference is the preparation of teachers where continuous education is not so crucial but definitely needed for best results.

\section{University level}

After a short introduction of the primary, secondary and vocational teachings methods of the overall concept, this paper will focus on the university level. On this level, a case study has been performed in two different target groups. One target group has been non-Mechatronic students (mechanical engineering students) and other Mechatronics bachelor level students on the frame of "Microcontroller and Practical Robotics" course. The second one is described more detail in this paper.

One of the most important success factors of this experience is the continuous education process and teacher support. One may think that the main obstacle would be the lack of proper funding's to buy the equipment or a lack of interest among the pupils. It turned out that the major success factor is the local teacher motivation [23]. Corresponding author has personal experience of helping to start the Robotic course in more than 50 schools around

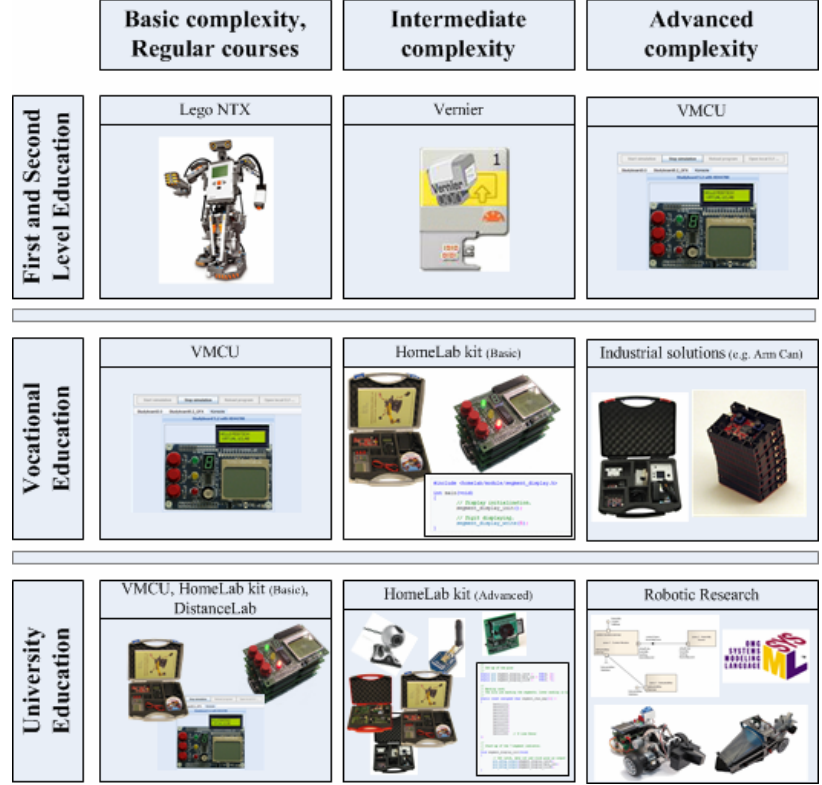

Figure 1. Embedded System and Robotic education path supported by diverse lab tools.

Estonia and educating more than 80 teachers during past three years. The experience shows that motivated and innovative teachers, even with lack of professional skills in Robotics, are the key factor to success when integrating robotic courses in schools. According to this conclusion, the key factor of strategic planning for a high school Robotic curriculum is a teachers training and continuous support in any aspect related to Robotic education.

\section{CURRICULUM CONTENT AND COURSE DESCRIPTION}

The concept described above is most intensively implemented at Tallinn University of Technology (TUT), Estonia and Bochum University of Applied Sciences (HBO), Germany, in cooperation with other international partner universities and local partner schools. For instance, the German vocational school "Berufskolleg am Haspel" as well as the Finnish "Prakticum Vocational College" are utilizing the concept and associated learning situations in their daily education. The overall concept is based on international cooperation and collaboration in the frame of several EU funded lifelong-learning projects, where all key users participated before. The case study, presented in this paper, is based on the two courses "Microcontrollers and Practical Robotics", and "Applied Computer Science for Mechatronics" where the novel blended teaching and learning concept is applied.

\section{A. Estonian university course "Microcontrollers and Practical Robotics"}

The first implementation of the case study is based at the Tallinn University of Technology (TUT) in Estonia in the frame of Mechatronics Bachelor studies. The curriculum named "Mechatronics" is a $3+2$ system curriculum (Bologna declaration) where students can enter into master level not only from Mechatronics bachelor but from basic studies and ending with a graduation thesis. In most cases, Robotic courses are included within the Mechatronics curriculum, but can also be an elective course for many other disciplines, like Computer Science, Electrical Engi- 

ACCOMPANIED BY 'ROBOTIC HOMELAB KIT'

neering, or Product Development, The robotic course can be selected by bachelor level students. It should be similar also to other engineering curricula. A Special study module is the main module where students are educated in the field of Mechatronics and Robotics. This module consists of the following courses:

- $\quad$ The $\mathrm{C} / \mathrm{C}++$ Language and Object-oriented Programming

- Microcontrollers and Practical Robotics

- Robot Systems and Sensor Technique - Project

- Industrial Training

These courses can be carried out in an integrated manner, meaning that for instance knowledge acquired in programming courses can be immediately applied in the Robotic courses. Project work within these courses is usually connected with industrial real life problems. The lecture-practice concept is set up in a blended learning environment, utilizing the tools described in Section III. The Course volume is defined as 4 ECP and it is ending with final graded test. In its set up, the course is divided into internal modules as following:

- Microcontroller basics and digital i/o

- Sensors

- Motors

- Robotic systems

Three first modules are providing knowledge and practical skills about single functionality whereas the last one Robotic Systems is integrating previously gained knowledge into system level where students have to complete small Robotic systems by programming behavior and making some electromechanical adaptations. The formal set up of the courses is described by supervisors, with one graph using Mindmap techniques. On the Fig. 2 the particular course setup in autumn 2011 is demonstrated

\section{B. German university course "Applied Computer Science for Mechatronics"}

The second curriculum is situated at Bochum University of Applied Sciences in Bochum (HBO), Germany. It is a seven semester, 180 ECTS point bachelor study and the curriculum is named "Mechatronics - Bachelor of Engineering". Core elements of this curriculum are:

Mechatronic components

- Systems Engineering

- Manufacturing Engineering

- Computer-aided design methods

- Mechatronics Design

- Materials Technology

- Engineering Mechanics

- Fluid Mechanics / Thermodynamics

During the first five semesters of the Bachelor study all students are studying the same content, but in sixth semester there is the option to choose an area of specialization or spend the semester abroad to gather new experiences. The overall sixth semester is counted with 30 ECTS points. One can choose between different specialization areas, like a.) Mechatronic Systems, b.) International Engineering, c.) Mechanical Construction, d.) Production or e.) Automotive.

The presented course in this paper is situated within the specialization area of "Mechatronic Systems" and belongs to the module "Applied Computer Science" (8ECTS). This module consists of "C-Programming" and "Image Processing" courses, where the "C-Programming" should be based upon embedded system technology.

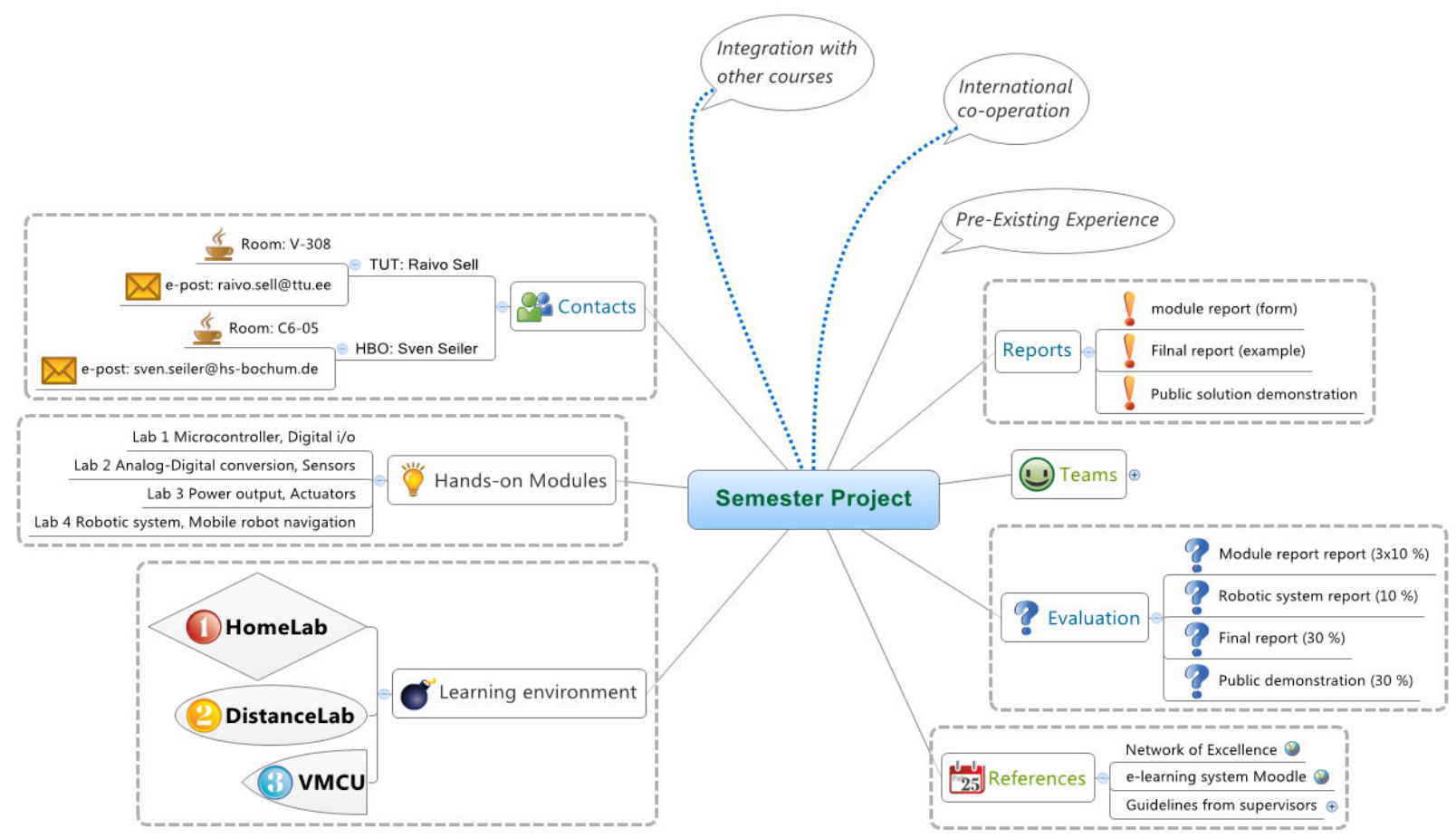

Figure 2. Example course set-up 

ACCOMPANIED BY 'ROBOTIC HOMELAB KIT'

The course volume is defined as $4 \mathrm{ECP}$ and it is ending in general with a final oral exam (or as a written one, depending on how many students attends the course). In its set up, the course is divided into internal modules as following:

- Microcontroller basic and digital i/o

- Sensors and Motors

- Robotic systems

- Object Oriented programming with $\mathrm{C}++$

The same Mindmap (but with different supervisor contact) as used for the Estonian course (fig. 2) is used for the course introduction in Germany.

As the courses have similarities, but not exactly the same outlines, there is a sligh difference in the emphasis on specific tools and methodologies. For instance, the German course is more focused on the embedded programming then on electronics and hardware. There are diverse approaches to adjust the tools and materials for different kinds of requirements. The course supervisor may hand ready build robots to the students or just give them a basis HomeLab module giving task to build own robots.

\section{High and vocational School activities}

The vocational school case study includes around ten different institutions where "Robotics" or "Embedded System" is a course in the school curriculum. The given concept can be applied on different levels of complexity (Figure 1), and therefore on different levels of educational institutions. When using the same tools and products, like Robotic HomeLab kit, Virtual Micro Controller Unit or the Distance Lab facility described in this paper and authors former publications in the frame of high or vocational school education, tasks are much simpler and students may use for instance a special programming library for easy access to the hardware. The focus is set on algorithms and basic programming, for instance a traffic light system with the Study Board. On university level, the Home Lab kit is taken as a base platform for robot construction projects, where students learn to work with low level hardware functionality of the underlying controller.

\section{Course set-up and concept}

The general course concept is following the "Robotic Blended Teaching \& Learning Concept" [13] and "Comprehensive Blended Learning Concept for teaching Micro Controller technology" [10] described below, where several cutting-edge e-learning technologies are applied. The overall approach is oriented on a semester-spanning student group project. The university course has its standard outline where students can get basic information, like credit points, evaluation criteria, basic content and arrangement information. Working process

The work starts of course with an introduction where all rules and procedures are introduced, by using same Mindmap graph, presented on Fig. 2. All course modules are executed in small groups as teamwork and one report has to be completed per team. Students at TUT start with self-teaching modules by using the Robotic HomeLab kit, but can continue practical work over the Internet by using either Virtual- or DistanceLab facilities. In case of HBO the students are using the VMCU solution.

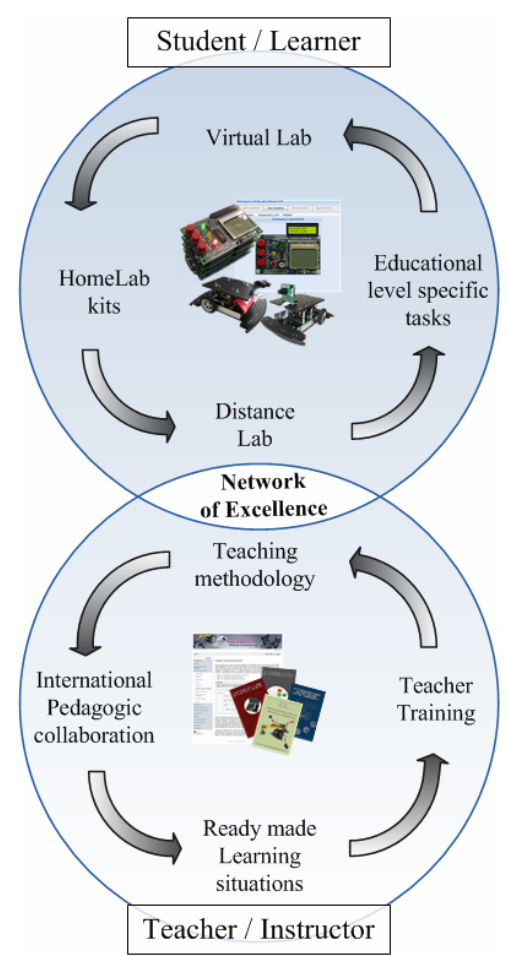

Figure 3. Coherence between learners and instructors in the didactical concept

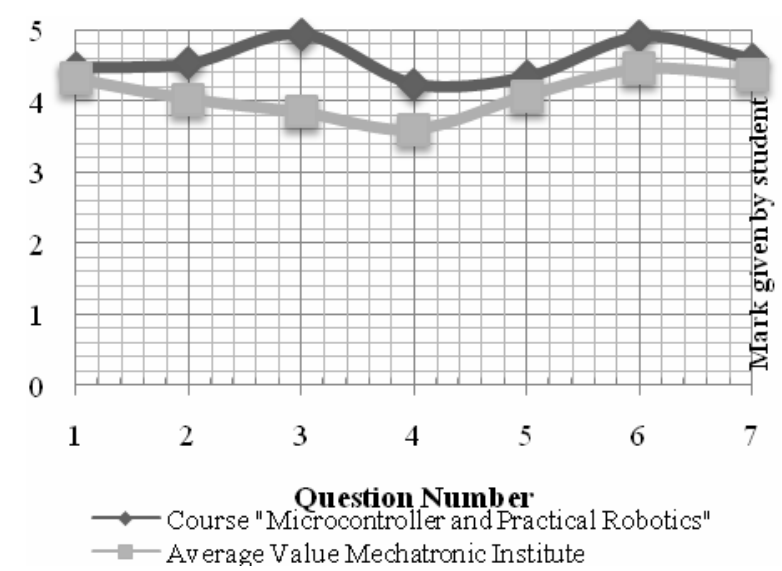

Figure 4. Distance learning evaluation of the course "Microcontrollers and Practical Robotics"

All systems are fully compatible and if a student (or group) creates a solution on the e.g. VMCU they can transfer the same source code to HomeLab kit hardware and it will work almost exactly like in the virtual environment. Of course simulated virtual and real components cannot behave completely identical, but the behavioural difference is marginal. To ensure continuous working the evaluation procedure is dispensed over the time of the course. Groups have to report at the end of every module and if needed, discussions will be held during the course meetings.

The final report is published directly on the web, into the HomeLab kit Community project space [18] where it is directly available to supervisors and has also direct public accessibility. Student groups get initial help from supervisors to do the labs but it is intended that they will do the main work after short introduction without direct supervision. An important aspect of the course is the final 

ACCOMPANIED BY 'ROBOTIC HOMELAB KIT'

public demo of the developed system. This motivates students to finalize the module. The public demo is also important to keep the time frame solid because if the date is fixed and audience asked there is no way to postpone the finalization of the project. Experience has shown that students are happy and proud to present their work in public even if they are afraid in the beginning. As an additional value, learners gain first experiences in public presentation.

\section{E. Hypothesis and pedagogical issues addressed}

The previous sections explained in detail the author's hypothesis and motivations behind the overall concept. The main assumption is, that enriching the teaching and learning process in Robotic education using Internet based tools and transforming the learning process to a logical sequential utilizing-chain of tools, will significantly enhance the students learning outcome. This learning outcome can be measured by the ability of students that are enabled to build their own robots in the end of the course. In addition the courses are built up active learning approaches, where the classical lecture is reduced and the focus is set on the semester project.

\section{F. Overview and didactic approach}

The overall concept involves both, the learners and the instructor's side, as presented in Fig. 3. While the learner is in contact with VMCU, HomeLab kit and DistanceLab, having specific tasks to fulfil with the given tools, the concept offers material for instructors' side in addition. For teachers the concept includes a teaching methodology and learning situations that can be directly applied into courses. It also offers international collaboration for teachers by utilising the "Network of Excellence", a wiki base web site with an internal area for teachers, where they can share exercises and to swap ideas on an international level. As last point there are also teacher seminars available (up to today only in Estonia) to train the trainers for giving courses with the Robotic concept material.

The unique contributions of the overall didactical approach are the three different levels of education that can be addressed by utilizing the same hardware using different course material. Figure 1 illustrates the following three different learning paths a.) First and second level education, b.) Vocational education and c.) University education.

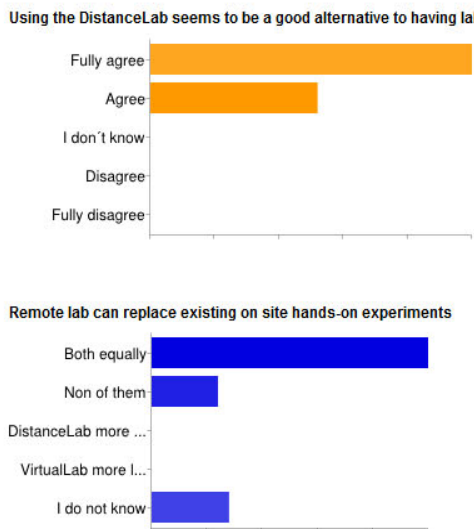

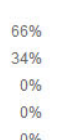

$0 \%$

\section{COURSE ENVIRONMENT}

At current time (Summer 2012) the presented course is running third year in TUT and in first year in Germany. Initially the course was designed for continuous education, mainly focusing on Robotics, computer science, electrical engineering and technology teachers at secondary and vocational schools. Later it was modified to comply also for regular courses at a bachelor level. Now, it is taught for both, students and for continuous education learners. In the case study course, implemented in autumn 2011 in Tallinn, 46 students in total were attending and 37 of them passed the course with mark 'excellent' or 'very good'.

\section{EvaluAtion}

\section{A. Student course and DistanceLab evaluation}

The presented evaluation was realised for the course "Microcontrollers and Practical Robotics", in Estonia. While having similar feedback about the course in Germany, there is no published evaluation, yet.

To prove the benefit of the described concept and the hypothesis stated before, authors asked students that participated in the course in Tallinn to fill a survey about distance learning (represented in the next section) in addition to the regular course evaluation, that is presented in Fig 4.

As the overall feedback was quite positive it was important to gather details about specific parts of the concept and how they have been accepted by the students. The regular course evaluation, which is asked to answer from all students that participated in the course a total number of 35 of 46 , filled the evaluation form in the last semester. As the overall grading of the courses at the Department of Mechatronics in Tallinn is very good in general (the maximum points that can be reached for each question is 5.00), the very high grades for "Quality and Provision of study material" ( $\{3\}$, with a value of 4.94$)$ and the "Use of Modern teaching methods and devices" ( $\{6\}$, with a value of 4.91) are still over average. The questions listed in table 2 correspond to the numbers on the X-axes in Fig. 4.

In addition to general course feedback the students were asked to fill in a GoogleDocs online survey. This survey was composed more detailed to cover the real course content and the tools that were used during the semester.
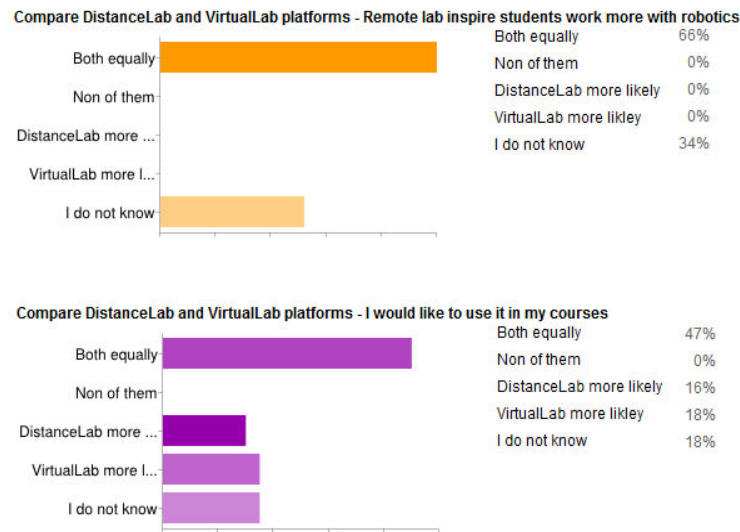

Figure 5. Feedback from teachers to a survey in a teacher training seminar about the tools of the Robotic Concept 

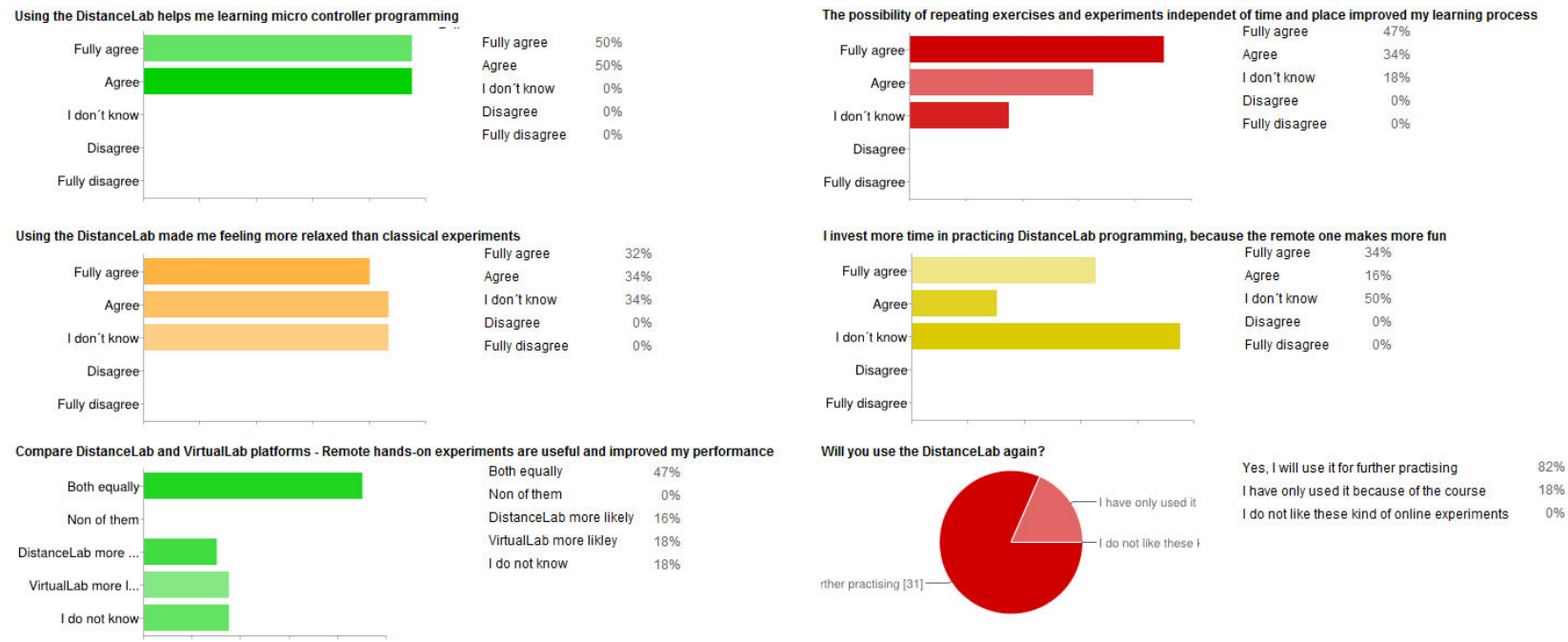

Figure 6. The student's feedback to the course "Microcontrollers and Practical Robotics"

In addition (during a teachers training seminar) the tools were presented to local school teachers in Estonia and they were asked about their opinion about the utilization of DistanceLab, VirtualLab and HomeLab kit in K-12 education. The student overall feedback is positive to all questions asked, as presented in the charts generated from the GoogleDocs survey in Fig. 5, almost 82\% state, that they like to use the DistanceLab again, even when the course is passed, while 47\% ("Fully Agree") and 34\% ("Agree") answered, that they see an improvement of their learning process due to being independent of time and place for their lab time.

\section{B. DistanceLab evaluation}

As stated before, authors also asked for feedback from teachers during a teachers training session. This train-thetrainer seminar is held on demand, but several times a year in Estonia to educate teachers on how to use the HomeLab kit and associated tools and on how to apply the learning concept in the daily education

In total, during the seminar, 38 teachers from vocational schools in the Tallinn area were asked after they have been introduced to the tools that are belonging to the teaching concept and having two hours of working with them. Their feedback is presented in Fig. 6. From their feedback DistanceLab, as well as VirtualLab (VMCU) could be a replacement for existing hands-on experimentations, as well as inspiring and engaging students in learning robotics. All of them are planning to use the tools in their K-12 courses, where $47 \%$ would like to use both, $16 \%$ the DistanceLab more likely, $18 \%$ VirtualLab more likely and another $18 \%$ that are unsure so far about the utilization of the concept.

\section{CONCLUSION AND LESSONS LEARNED}

The overall concept for the education of microcontroller and robotics with its subparts, HomeLab kit, DistanceLab, VirtualLab and corresponding learning and course material was successfully implemented into the university educational process in the courses "Microcontrollers and Practical Robotics" at Tallinn University of Technology and "Applied Computer Science for Mechatronics" at Bochum University of Applied Sciences. In addition the concept was applied and tested within a K-12 course for ongoing computer scientist at German "Haspel Vocational School" and several Estonian vocational schools and high schools. The feedback to the concept is positive and the concept was accepted by nearly all participants. Only a small subset of learners was not sure $(18 \%$, Fig. 5, upper right) about their improved learning process.

\section{ACKNOWLEDGMENT}

This research, development and case study was realized by funding of the European Commission Education and Training in the funding scheme "Leonardo da Vinci" by the projects "VAPVoS" and "NetLab" and the Estonian Science Foundation grant No. 8652.

\section{REFERENCES}

[1] Alexa - The web information company, "Top Sites", [Online]. Available: http://www.alexa.com/topsites

[2] ARD/ZDF-Onlinestudien 2004-2011, "Average length of stay for online use from 2002 to 2010", [Online]. Available: http://www.ard-zdf-onlinestudie.de/index.php?id=319 (Webpage in German language)

[3] Abulrub, A., Attridge, A., \& Williams, M. (2011). Virtual Reality in Engineering Education: The Future of Creative Learning. International Journal Of Emerging Technologies In Learning (IJET), 6(4). Retrieved August 21, 2012, from http://onlinejournals.org/i-jet/article/view/1766/2019

[4] Ivanović, M., Xinogalos, S., \& Komlenov, . (2011). Usage of Technology Enhanced Educational Tools for Delivering Programming Courses. International Journal Of Emerging Technologies In Learning (IJET), 6(4). Retrieved August 21, 2012, fromhttp://online-journals.org/i-jet/article/view/1796/2011

[5] González, A., García, C., \& Candela, S. (2011). Providing Learning Computing Labs using Hosting and Virtualization Technologies. International Journal Of Emerging Technologies In Learning (IJET), 6(S2). Retrieved August 21, 2012, from http://onlinejournals.org/i-jet/article/view/1651/1746

[6] Uvais Qidwai. 2011. Fun to learn: project-based learning in robotics for computer engineers. ACM Inroads 2, 1 (February 2011), 42-45. $\mathrm{DOI}=10.1145 / 1929887.1929904$ http://doi.acm.org/10.1145/1929887.1929904

[7] Project Netlab and VAPVoS Team, Robotic HomeLab kit, [Online]. Available: http://home.roboticlab.eu/en/kit/

[8] Project Netlab Team, DistanceLab, [Online]. Available: http://distance.roboticlab.eu/ 

ACCOMPANIED BY 'ROBOTIC HOMELAB KIT'

[9] Project VAPVoS Team, Virtual Micro Controller Unit - Online System, [Online]. Available: http://vmcu.ihoch2.de/

[10] Seiler, S.; Sell, R.: 'Comprehensive Blended Learning Concept for teaching Micro Controller technology utilising HomeLab kits and Remote Labs in a virtual web environment', invited paper to Lecture Notes on Computer Science, Transactions on Edutainment, Number 7544, 2012, ISSN: 1867-7207, Springer,Germany (accepted for publication)

[11] Seiler, Sven; Sell, Raivo; Ptasik, Dennis, Boelter, Martin, 'Holistic web-based Virtual Micro Controller Framework for research and education', International Journal of Online Engineering, Vol. 8, 2012

[12] S. Seiler, R. Sell, Comprehensive Blended Learning Concept for Teaching Micro Controller Technology, in eLearning Baltics 2011. Proceedings of the 4th International eLBa Science Conference, Rostock (Germany) May 26-27, 2011, ISBN 978-3-83960258-4, pp. 15-24.

[13] Sell, R., Seiler S.: Improvements of Multi-disciplinary Engineering Study by Exploiting Design-centric Approach, Supported by Remote and Virtual Labs , International Journal of Engineering Education Vol. 28, No. 4, pp. 1-8, 2012

[14] R. Sell, S. Seiler, Integrated Concept for embedded system study, in MSM 2011. Proceedings of the 7th International Conference Mechatronic Systems and Materials (MSM 2011). July 7-9, 2011, Kaunas, Lithuania, ISSN 1822-8283.

[15] Seiler, S., Sell, R.: Virtual Academy Platform Supported by a Semantic Knowledge Base. In: Proc. of the 7th International Conference of DAAAM Baltic, 22-24 April 2010, Tallinn, Estonia, (2010).

[16] S. Seiler, C. Köhn, R. Sell, T. Otto, INNOVATIVE STUDY KIT FOR ADVANCED MECHATRONIC EXPERIMENTS, 9th International Workshop on Research and Education in Mechatronics. September 18-19, 2008, Bergamo, Italy, ISBN: 88-88412-33-6

[17] Titzer, B. L.: Avrora - the AVR simulation and analysis framework. Morgan Kaufmann, University of California, Los Angeles (2004)
[18] Project Netlab and VAPVoS Team, Robotic HomeLab Community, [Online]. Available: http://home.roboticlab.eu/

[19] Sell, R., Leini, M.: "Microcontroller \& Practical Robotics", TUT Press, Tallinn, Estonia (2011)

[20] Kremer, M., Bernhard, D., Seiler, S., Ptasik, D., Koehn, C.: "Study Material fuer HomeLab kit und Virtual Labs", in Modern Shared Robotic Environment, 14 September, 2011, Bochum, Germany, ISBN 978-3-00-035131-7

[21] Seiler, S., Ptasik, D., Tueselmann, K., Koehn, C.: "eCurriculum fuer die Mikrocontrollerausbildung unter Einsatz von Remote Laboratories und Virtual Labs", in Modern Shared Robotic Environment, 14 September, 2011, Bochum, Germany, ISBN 978-300-035132-7

[22] Hellgren, M., Sell, R., Seiler, S. et al: Hands-On Lab Exercises. Vilnius PU Press, Lithuania (2008)

\section{AUTHORS}

Sven Seiler, is with the Electrical Engineering and Computer Science Department, Bochum University of Applied Sciences, Bochum, Germany (e-mail: sven.seiler@hs-bochum.de)

Raivo Sell, is with the Department of Mechatronics, Tallinn University of Technology, Estonia (e-mail: raivo.sell@ttu.ee).

Dennis Ptasik, is with the Electrical Engineering and Computer Science Department, Bochum University of Applied Sciences, Bochum, Germany (e-mail: dennis.ptasik@hs-bochum.de)

Received 22 August 2012. Published as resubmitted by the authors 3 December 2012 . 